\title{
Retos del posconflicto frente a la respuesta humanitaria: entre la persistencia de las consecuencias humanitarias y las limitaciones al mandato de los actores humanitarios
}

\author{
Recibido: 9 de octubre de 2018 - Aprobado: 17 de octubre de 2019 \\ https://doi.org/10.22395/ojum.v19n38a9 \\ Paula Andrea Valencia Londoño**
}

\section{RESUMEN}

El acuerdo de paz entre el Gobierno de Colombia y las Fuerzas Armadas Revolucionarias de Colombia-Ejército del Pueblo (FARC-EP) se firmó en el año 2016. A pesar de que este marcó un hito en la historia del país y constituye un paso importante en la búsqueda de salidas negociadas al conflicto armado y la reducción de la violencia, ha traído en el periodo de posacuerdo un proceso de desestabilización sociopolítica que ha derivado en múltiples vulneraciones de los derechos humanos, tanto en zonas rurales como urbanas. Estas se expresan en la persistencia de consecuencias humanitarias que, aunque ya no se derivan de una situación de conflicto armado no internacional, sino de la confrontación entre actores armados ilegales vinculados con el crimen organizado, son clara expresión del impacto de la lucha armada sobre la población civil. En múltiples ocasiones, estas consecuencias han llegado a niveles equiparables a los de las manifestaciones presentes en situaciones de conflicto armado. No obstante, cada vez la respuesta humanitaria amparada por el espectro normativo del DIH es más limitada, lo que hace que esta se convierta en uno de los principales retos de la etapa del posconflicto.

Palabras clave: acción humanitaria; posacuerdo; violencia armada; gestión del riesgo.

Este análisis es resultado de la tesis El humanitarismo maximalista en contextos de violencia armada urbana: una mirada desde la construcción de paz. El caso de Medellín, para optar al título de doctora, del Programa de Doctorado en Ciencias Sociales de la Universidad de Granada. Particularmente se retoma información del estudio de caso del Movimiento Nacional de Gestores de Paz, realizado en convenio con la ONG Internacional World Vision. Por otro lado, algunas reflexiones en materia de urbanismo son derivadas del proyecto de investigación Análisis comparativo de la evaluación del impacto social, ambiental y territorial de los proyectos urbanos desarrollados en dos ciudades de América Latina (Medellín y Foz de Iguazú)", el cual fue cofinanciado por la Universidad de Medellín, la Universidad de San Buenaventura y el Colegio Mayor de Antioquia.

** Comunicadora social y periodista, estudios de Derecho y Ciencias Políticas, especialista en Gestión Regional del Desarrollo, magíster en Estudios Avanzados, magíster en Estudios Interdisciplinarios de Desarrollo, experta en Gestión de la Paz y los Conflictos, doctora en Ciencias Sociales. Coordinadora, Centro de Investigaciones en Ciencias Sociales y Humanas, Universidad de Medellín, Medellín, Colombia. Correo electrónico: pvalencia@udem.edu.co. Orcid: http://orcid.org/0000-0002-1077-6959 


\title{
Challenges of the Post-Conflict Regarding the Humanitarian Response: Between the Persistence of the Humanitarian Consequences and the Limitations to the Mandate of Humanitarian Actors
}

\begin{abstract}
The peace agreements between the Colombian government and the Colombian Revolutionary Armed ForcesPeople's Army (FARC-EP) was signed in 2016. Despite it being a historical milestone and constituting an important step in the search for a negotiated end to the armed conflict and a decreasing of violence, it has brought with it a social and political destabilization with multiple human rights violations as an outcome, both in rural and urban areas. These are expressed in the persistence of humanitarian consequences that even though they are no longer derived from a non-international armed struggle but a confrontation between illegal armed forces linked with organized crime, are a clear expression of the impact of the armed struggle in the civilian population. On multiple occasions, these consequences have reached levels comparable to those of the phenomena of an armed struggle. Nonetheless, the humanitarian response protected by the normative spectrum of the IHL is more limited every day, which makes it one of the main challenges of this phase of the post-conflict.
\end{abstract}

Keywords: humanitarian action; post-agreement; armed violence; risk management.

\section{Desafios do pós-conflito ante a resposta humanitária: entre a persistência das consequências humanitárias e as limitações ao mandato dos atores humanitários}

\begin{abstract}
RESUMO
O acordo de paz entre o governo da Colômbia e as Forças Armadas Revolucionárias da Colômbia-Exército do Povo foi firmado em 2016. Embora tenha sido um marco na histórica do país e constituído um passo importante na busca de soluções negociadas para o conflito armado e para a redução da violência, vem trazendo, no período de pós-acordo, um processo de desestabilização sociopolítica que deriva em múltiplas vulnerações dos direitos humanos tanto em áreas rurais quanto em urbanas. Essas violações são expressas na persistência de consequências humanitárias que, ainda que não derivem de uma situação de conflito armado não internacional, mas sim do confronto entre atores armados ilegais vinculados com o crime organizado, são clara expressão do impacto da luta armada sobre a população civil. Em várias ocasiões, essas consequências chegaram a níveis incomparáveis aos das manifestações presentes em contextos de conflito armado. Contudo, cada vez mais, a resposta humanitária amparada pelas regulamentações do Direito Humano Internacional é limitada, o que faz com que isso se converta em um dos principais desafios da etapa do pós-conflito.
\end{abstract}

Palavras-chave: ação humanitária; pós-acordo; violência armada; gerenciamento do risco. 


\section{INTRODUCCIÓN}

La situación de conflicto armado que ha vivido Colombia por más de sesenta años ha generado en el país una tradición que no solo tiene que ver con marcos normativos y políticas públicas estructuradas a la luz de los postulados del DIH. Antes bien, afecta de forma más general la construcción de un andamiaje institucional para la respuesta humanitaria, centrado en la complementariedad y subsidiariedad entre actores públicos y agentes humanitarios internacionales. Este andamiaje institucional se convirtió en elemento clave para la consolidación de infraestructuras que viabilizaron, tanto la respuesta humanitaria de emergencia como los procesos de atención a las víctimas para el restablecimiento de derechos.

Sin embargo, el entorno actual de las grandes ciudades de Colombia, en especial de Medellín, se asemeja cada vez más a la situación de conflictividad armada presente en los grandes conglomerados latinoamericanos. En estos las fronteras entre crimen organizado, delincuencia común y violación a gran escala de los derechos humanos, como lo afirma Kaldor (2001) desde su definición de nuevas guerras, produce la emergencia - en el caso colombiano persistencia - de consecuencias humanitarias similares a las de los conflictos armados clásicos, pero en ciudades que se encuentran en paz' (Lucchi, 2010; Harroff-Tavel, 2010).

Los recurrentes periodos de transición que ha vivido Colombia en los últimos treinta años se han originado en los múltiples procesos de paz adelantados con los diferentes actores armados que han entrado en la escena política. Estos periodos se han constituido en importantes pasos para la búsqueda de una paz negativa. No obstante, también han presentado variaciones en las dinámicas de las confrontaciones armadas en el país que se expresan en dos aspectos. El primero es el cambio de escenarios, del rural como espacio paradigmático del conflicto armado interno al urbano como espacio propicio para la violencia armada. El segundo tiene que ver con la presencia de múltiples actores, lo que ha llevado a la coexistencia, casi hasta la indistinción, entre subversión, delincuencia y crimen organizado.

Sin embargo, hay un elemento que no ha variado con el pasar de los años: las consecuencias humanitarias de la confrontación armada sobre la población civil. Estas persisten y hasta se incrementan en muchos casos, a pesar de que la tendencia cada vez más clara es la disminución y casi desaparición en ciertos territorios de la situación de conflicto armado interno en términos del DIH. Esta contradicción tiene importantes implicaciones en términos de la pérdida de soporte jurídico para el accionar de los actores humanitarios.

Entendida esta desde una perspectiva de paz negativa (Galtung, 2003) como ausencia de conflicto armado no internacional. 
No se puede desconocer que la paradoja entre la disminución del accionar de los actores armados comprendidos por el DIH y el incremento de consecuencias humanitarias fue subsanada gracias a la confluencia entre una situación de conflicto armado no internacional y las manifestaciones de crimen organizado y delincuencia que se expresaban en las ciudades en forma de violencia armada. Esto permitió que, por casi dos décadas, la respuesta humanitaria fuera constante a pesar de la transición en las formas de confrontación.

Solo a partir de 2005, con el proceso de desmovilización paramilitar, comenzó el descenso de la presencia de organizaciones humanitarias internacionales en las grandes ciudades, especialmente de las organizaciones vinculadas al sistema de Naciones Unidas. Además, tras la firma del acuerdo de paz, se aceleró la tendencia de salida inmediata para dar paso a agencias dedicadas a la consolidación de la paz.

Esta situación pone a la población civil en el panorama desalentador de las urbes latinoamericanas que enfrentan fenómenos de violencia armada urbana. El Estado, en su pérdida de gobernabilidad, es incapaz de dar respuesta a la población víctima porque tiene dentro de su propio territorio zonas vedadas donde no puede ejercer su función de protección (Harroff-Tavel, 2010). Por otro lado, las organizaciones humanitarias, desde su mandato clásico, se encuentran constreñidas para operar en estos nuevos escenarios de confrontación, lo que imposibilita la generación de un espacio humanitario.

El foco de interés de este artículo se centra en varias preguntas: ¿Existe la posibilidad de generar una respuesta a las consecuencias humanitarias derivadas de situaciones de confrontación armada que escapen la definición clásica del DIH?, ¿Qué aprendizajes deja el caso colombiano de la confluencia por décadas de fenómenos de violencia claramente imbricados con una situación de conflicto armado no internacional? Para responder estas preguntas, el texto inicia con una breve descripción de la situación de conflicto armado colombiano y su relación con otras manifestaciones de violencia ajenas a la órbita del DIH. En segundo lugar, el análisis se traslada al caso de Medellín y aborda cómo las consecuencias humanitarias persisten y se incrementan en una tendencia contraria a la desaparición de la escena política de los actores armados tradicionales. En tercer lugar, se caracterizan las dos vertientes en materia de acción humanitaria: humanitarismo minimalista y humanitarismo maximalista y se presentan las potencialidades de la acción humanitaria maximalista en contextos de paz. Finalmente, el artículo cierra con un ejemplo de la puesta en marcha de acción humanitaria maximalista desde la órbita de la atención a desastres en el contexto de Medellín. 


\section{Método}

El análisis de caso que soporta este artículo hace parte de la fase descriptiva-diagnóstica del proyecto de investigación de tesis doctoral El humanitarismo maximalista en contextos de violencia armada urbana: Una mirada desde la construcción de paz. El caso de Medellín. A través de este se buscó la construcción de una caracterización de la problemática mediante un modelo de estudio de casos múltiples (Neiman y Quaranta, 2006) orientado a responder a la pregunta: ¿Qué tipo de capacidades tendientes a la construcción de paz es posible desarrollar desde las intervenciones basadas en un humanitarismo maximalista, en contextos de violencia armada urbana?

Para ello se realizó el estudio de dos intervenciones humanitarias:

1. El Proyecto Ecopad, ejecutado de forma directa por la ONG Internacional Word Visión International.

2. El proyecto Casa de Derechos, ejecutado por la Defensoría de Pueblo y financiado por Acnur.

La primera intervención hace parte de la línea de trabajo en temas humanitarios de esta ONGI y es el estudio de caso en el cual nos centraremos en la parte final este artículo.

Con el fin de determinar este tipo de capacidades, se utilizó como marco teórico general de orientación el enfoque de capacidades de Sen $(1996,1998)$, que se complementó, para la construcción del esquema categorial, con la propuesta de intervención contenida en la Guía sobre salud mental y apoyo psicosocial en emergencias humanitarias y catástrofes del Clúster Protección de Interagency Standing Committe —IASC— (2007).

De otro lado, para aproximarse al estudio de caso — que se aborda al final del artículo— se hizo uso de cuatro técnicas para la recolección de información: revisión documental, encuestas, entrevistas semiestructuradas ${ }^{2}$ y grupos focales ${ }^{3}$ (ver tablas 1 y 2). De manera particular, con el fin de realizar un análisis de las capacidades desarrolladas por los niños, niñas y jóvenes que participan o participaron en el proyecto Ecopad, se aplicó una encuesta construida con base en las preguntas referentes a habilidades cognitivas para la solución de problemas del Cuestionario de Habilidades de Interacción Social (CHIS), diseñado por Monjas (1994) y por Monjas y González (2000).

2 El cuestionario fue aplicado por escrito a la ONGI Word Visión y en entrevista directa en la Casa de Derechos.

3 Esta técnica fue empleada con las mujeres que participan en los programas de la Casa de Derechos y con los niños, niñas y jóvenes que hicieron parte del programa Ecopad o participan del Movimiento Nacional de Gestores de Paz. 
Tabla 1. Documentos analizados en la revisión documental

\begin{tabular}{|c|c|c|}
\hline Proyecto Ecopad & $\begin{array}{c}\text { Programa Movimiento } \\
\text { Nacional de Gestores de Paz }\end{array}$ & Casa de Derechos \\
\hline $\begin{array}{l}\text { Modelo de organización y participación co- } \\
\text { munitaria World Vision Colombia, Equipos } \\
\text { Comunitarios para la Acción Humanitaria y } \\
\text { el Desarrollo (Ecopad). Abril de } 2015 .\end{array}$ & $\begin{array}{l}\text { Diagnóstico de los sis- } \\
\text { temas de protección de } \\
\text { la niñez y la adolescen- } \\
\text { cia en Colombia. }\end{array}$ & $\begin{array}{l}\text { Informe } 2015 \text { para el defen- } \\
\text { sor del pueblo. }\end{array}$ \\
\hline $\begin{array}{l}\text { Informe de línea base del proyecto de } \\
\text { fortalecimiento nacional de los Equipos } \\
\text { Comunitarios para la Prevención y } \\
\text { Atención de Desastres (Ecopad) 2012-2014. } \\
\text { Visión Mundial Colombia, marzo de 2012. }\end{array}$ & $\begin{array}{l}\text { Presentación del } \\
\text { Movimiento Gestores } \\
\text { de Paz. }\end{array}$ & $\begin{array}{l}\text { La estrategia de atención } \\
\text { especializada de la dele- } \\
\text { gada para los derechos de } \\
\text { la población desplazada en } \\
\text { las Casas de los Derechos. }\end{array}$ \\
\hline \multirow[t]{2}{*}{$\begin{array}{l}\text { Informe de la evaluación final del proyecto } \\
\text { de fortalecimiento nacional de los Equipos } \\
\text { Comunitarios para la Prevención y Atención } \\
\text { de Desastres - Ecopad } 191301 \text {. Asuntos } \\
\text { humanitarios y emergencias. Programa } \\
03759,8 \text { al } 30 \text { de septiembre de } 2014 . \\
\text { Informe final de Visión Mundial Colombia. }\end{array}$} & $\begin{array}{l}\text { Presentación de los ob- } \\
\text { jetivos del Movimiento } \\
\text { Gestores de Paz. }\end{array}$ & $\begin{array}{l}\text { Línea de tiempo de la Casa } \\
\text { de Derechos. }\end{array}$ \\
\hline & $\begin{array}{l}\text { Plan estratégico del } \\
\text { Movimiento Gestores } \\
\text { de Paz. }\end{array}$ & \\
\hline
\end{tabular}

Fuente: elaboración propia.

Tabla 2. Muestra utilizada para la aplicación de las encuestas

\begin{tabular}{|c|c|c|c|}
\hline Grupos & Universo & Muestra & Tipo de muestra \\
\hline Ecopad & 21 & 7 (un niño y seis niñas). & $\begin{array}{l}\text { A oportunidad (no fue posible localizar } \\
\text { a un buen número de los integrantes } \\
\text { del proyecto, el cual terminó su ejecu- } \\
\text { ción hace alrededor de dos años). }\end{array}$ \\
\hline $\begin{array}{l}\text { Gestores } \\
\text { de paz }\end{array}$ & 150 & $\begin{array}{l}90 \text { (45 mujeres, } 42 \text { hombres, } \\
3 \text { no responden). }\end{array}$ & $\begin{array}{l}\text { Muestreo aleatorio simple. Nivel de } \\
\text { confianza del } 97 \% \text { y un nivel de error } \\
\text { del } 7 \% \text {. }\end{array}$ \\
\hline \multirow{2}{*}{$\begin{array}{l}\text { Grupo de } \\
\text { control }\end{array}$} & & $\begin{array}{l}78 \text { ( } 37 \text { mujeres, } 37 \text { hombres, } \\
4 \text { No responde). }\end{array}$ & \\
\hline & & $\begin{array}{l}42 \text { hacen parte de una activi- } \\
\text { dad extracurricular. }\end{array}$ & \\
\hline
\end{tabular}

Fuente: elaboración propia.

La información recolectada fue codificada y analizada con el apoyo del software "N- Vivo", el cual permitió la comparación de las categorías de análisis y su ordenación, para dar respuesta a la pregunta de investigación y finalmente al objetivo de indagación. 


\section{LA CONFLUENCIA DE CONFLICTO ARMADO, CRIMEN ORGANIZADO Y DELINCUENCIAS EN COLOMBIA: ORIGEN DE LA PERSISTENCIA EN LAS CONSECUENCIAS HUMANITARIAS}

En Colombia existen dos fenómenos que parecen actuar de forma aislada en otros contextos: el conflicto armado interno y la violencia criminal. Ambos demuestran claras correlaciones que han permitido un abordaje humanitario de las consecuencias de las múltiples violencias que vive el país. Pero hasta hace una década no se cuestionaba la legitimidad de los actores humanitarios internacionales para actuar ante problemáticas mixtas.

Las diferentes corrientes académicas que han inspirado el análisis de los factores causales de la confrontación armada colombiana y las razones de su prolongación dan cuenta de la imbricación entre variadas formas de confrontación armada (Valencia, 2018). A las causas sociopolíticas del surgimiento y prolongación del conflicto armado colombiano desde los sesenta (Guzmán et al., 2005), se sumó en los ochenta una lectura que vinculaba las manifestaciones urbanas y, en particular, el fenómeno del narcotráfico con la dinámica de la confrontación armada, lo que permitió una aproximación a otras vertientes de análisis desde la perspectiva de la empresa criminal (Collier, 2010; Deas y Gaitán, 1995; Gaitán, 2001; Deas, 2015).

Entre finales de la década del cincuenta e inicios de la década del sesenta se conformó la Comisión Nacional Investigadora de las Causas de la Violencia por parte del presidente Alberto Lleras Camargo. Con esta comisión se inicia en Colombia una tradición en materia de estudios sobre el conflicto armado (Uribe, 2011), la cual tiene como punto de partida el libro La violencia en Colombia de Germán Guzmán Campos, Orlando Fals Borda y Eduardo Umaña Luna (2005). Esta obra marca una tendencia de aproximación a nuestra confrontación armada desde una perspectiva estructural funcionalista que privilegiaba el análisis desde variables sociopolíticas. Esta tendencia es seguida en los ochenta por la naciente Comisión de Estudios sobre la Violencia. Pero esta nueva iniciativa creada para el análisis del conflicto armado introduce un elemento adicional que abre la puerta para la inclusión de factores que escapan a la perspectiva de guerra irregular (Sánchez y Meertens, 1983). Esta Comisión vincula al análisis de los factores determinantes del conflicto las diversas violencias que vivía en el momento el país, las cuales ya no solo estaban ligadas a la lucha insurgente, sino también a las problemáticas del narcotráfico y el traslado de la violencia rural a los centros urbanos.

Es así como el narcotráfico y la violencia armada urbana, con la ruptura que implican en materia de conflicto armado no internacional (desde la perspectiva del DIH), se convirtieron a partir de ese momento en condicionantes y motivadores de nuevas formas de aproximación al análisis de la confrontación armada. No se desconocieron los fuertes vínculos entre actores tradicionales del conflicto armado - guerrillas y 
autodefensas - y nuevos actores armados, pero se introdujeron en el análisis nuevas manifestaciones, actores y motivaciones de la violencia (Deas y Gaitán, 1995; Gaitán, 2001; Medina, 2008; Deas, 2015).

Este proceso complejo de analizar las violencias presentes en el contexto colombiano lleva al surgimiento de una nueva perspectiva de estudio que se aleja de posiciones estructuralistas. Involucra, más bien, la agencia individual como un factor determinante que se basa en la idea de empresa criminal (Collier y Hoefflerd, 2000; Collier, 2010) y la metáfora de codicia y agravio. Esta encuentra en los altos niveles de impunidad y en la inoperancia del aparato judicial sus mayores incentivos (Deas y Gaitán, 1995; Gaitán, 2001; Medina, 2008; Deas, 2015).

Las alianzas y transiciones de guerrillas y autodefensas, actores cubiertos por la órbita del DIH, con narcotraficantes y actores criminales tienen un largo historial en Colombia (Duncan, 2014; Valencia, 2018). La acumulación masiva de tierras, llamada por InSight Crime (s. f.) contrarreforma agraria, catapultó el ascenso del narcotráfico a la elite terrateniente, "siendo la excusa perfecta para integrarse en la lucha contrainsurgente" (Valencia, 2018, p. 60). Ejemplo de ello es el caso de los hermanos Castaño, quienes transitaron del narcotráfico a la conformación de ejércitos de autodefensas para apaciguar la violencia guerrillera (Duncan, 2014). En los noventa y a principios de 2000, el efecto de esta mutación entre actores armados fue el incremento exponencial de las consecuencias humanitarias en el país, expresadas en masacres, desplazamientos forzados por la violencia, homicidios selectivos, amenazas a líderes, accidentes por minas antipersonal, reclutamiento, violencia sexual, entre otras. Dicho fenómeno también se observa recientemente debido al alto grado de autonomía y legitimidad que la protección privada violenta (Bedoya, 2010) adquiere en la lucha por el control territorial luego de la firma del acuerdo de paz, nuevamente expresado en el repunte de las consecuencias humanitarias.

El desplazamiento forzado es la consecuencia humanitaria más emblemática y, por tanto, la que ha contado con un seguimiento más sistemático. Colombia sigue ocupando el segundo lugar a nivel mundial con mayor población desplazada, solo antecedida por Siria. En el periodo 2015- 2017 (durante el cese bilateral al fuego con las FARC, la firma del acuerdo de paz y el inicio de la fase de implementación) fueron desplazadas individualmente en el país 487.129 personas y 42.694 fueron víctimas de eventos masivos de desplazamiento, lo que representa un promedio de 13.500 personas por mes. En 2017139.359 personas fueron desplazadas, un aumento del 6 \% con respecto al 2016 (Oficina para la Coordinación de Asuntos Humanitarios Naciones Unidas [OCHA]-Umaic, 2018). No obstante, los porcentajes de población desplazada por perpetrador dan cuenta de la fluctuación en el origen de esta consecuencia humanitaria. En el 2017 solo un 30 \% de los desplazamientos fueron generados por la guerrilla, un $27 \%$ fue atribuible a bandas criminales, pero lo más preocupante es que 
el $42 \%$ no tuvo un perpetrador identificable (OCHA-Umaic, 2018). En este sentido, la OCHA-Umaic (2018) afirma:

Después de años de mejora (2015-2016), en 2017 se evidencia el deterioro de indicadores humanitarios. Entre enero y diciembre de 2017 las personas desplazadas en eventos masivos aumentaron el $48 \%$ del promedio registrado entre los años de mejora mencionados, aun con un actor armado menos que hacía parte del conflicto armado en Colombia (FARC-EP). Si bien se registra un impacto positivo en el período de los diálogos de paz, a partir de la firma del acuerdo de paz entre el Gobierno y las FARC-EP, los eventos que causan los desplazamientos obedecen a las nuevas dinámicas de la violencia, dada la expansión, surgimiento y/o reconfiguración de nuevos actores armados, quienes se disputan el control de los territorios dejados por las FARC-EP por los intereses que representan las economías ilícitas (cultivos ilícitos, minería ilegal). (p. 4)

Desde una perspectiva de análisis territorial, el 75 \% de los desplazamientos masivos ocurridos en 2017 se concentraron en la región Pacifico, seguida del 14 \% en el departamento de Norte de Santander, zona de frontera con Venezuela, y el 11 \% res tante se ubicó en la noroccidente y sur del país (OCHA-Umaic, 2018).

La Acnudh ha observado que otros grupos armados, como el ELN, así como organizaciones criminales, han incursionado en las antiguas zonas de influencia de las FARC-EP, a menudo buscando controlar las economías ilegales, lo que ha tenido un impacto negativo en los derechos de los habitantes (Oficina del Alto Comisionado de las Naciones Unidas [ACNUDH], 2018, p. 2).

Esta tendencia creciente en materia de consecuencias humanitarias se consolidó en 2018. Este año, según OCHA-Umaic (2019) la situación humanitaria superó las cifras de los cinco años anteriores. Su mayor expresión fue de nuevo el aumento de los desplazamientos masivos. Las cifras llegan a doce eventos que afectaron a 33.403 personas. El 92 \% se focaliza en los departamentos Norte de Santander, Nariño y Antioquia. Además, 1.119.912 personas sufrieron restricciones a la movilidad y al acceso a bienes, servicios, asistencia y derechos fundamentales, un 708 \% más que en 2017.

En particular, la dinámica del desplazamiento forzado, que a simple vista sería una consecuencia humanitaria del conflicto armado interno, "deja ver sus claros vínculos con estructuras criminales asociadas al narcotráfico que se nutrieron de la expropiación de tierras" (Centro Nacional de Memoria Histórica [CNMH], 2013). De ahí su incremento en la etapa de posacuerdo.

La confluencia entre conflicto armado y crimen organizado también se ve expresada claramente en el lugar que ocupan los homicidios dentro de las consecuencias humanitarias con mayores tasas en el país. Entre enero de 2015 y diciembre de 2017 se produjeron seiscientos cincuenta y cuatro homicidios intencionales en persona protegida, lo que representa un aumento del 396 \% (OCHA-Umaic, 2018). El mayor 
número de estos se presentaron en los departamentos de Arauca (Saravena, Tame, Arauca), Nariño (Tumaco), Cauca (Caloto, Suarez, Patía) y Norte de Santander (Tibú), pero también en ciudades capitales como Medellín y cascos urbanos como San José de Uré y Tierralta (Córdoba) (OCHA-Umaic, 2018). En 2018 estos ataques contra la población civil, representados principalmente en amenazas y homicidios intencionales en persona protegida aumentaron en un $26 \%$ con respecto a 2017, donde los principales responsables son grupos armados desconocidos (OCHA-Umaic, 2019) Como afirma la OCHA-Umaic (2018), esto evidencia "extensión de la violencia armada hacia zonas urbanas y otras ciudades intermedias, además de una interrelación compleja entre criminalidad" (p. 22).

Así, la preocupación actual sobre los actores generadores de las consecuencias humanitarias se ha trasladado de la lucha insurgencia-contrainsurgencia al accionar de los grupos armados después de la desmovilización, quienes concentran el dominio social y territorial de un vasto territorio del país y hacen de la población civil objetivo primario y deliberado de su accionar (Kalyvas, 2001) como mecanismo para mantener su poder local.

\section{MEDELLÍN: EL TRÁNSITO DE UNA SITUACIÓN DE CONFLICTO ARMADO INTERNO A UNA SITUACIÓN DE VIOLENCIA ARMADA. EL IMPACTO EN LAS CONSECUENCIAS HUMANITARIAS}

En el caso de Medellín, la lucha armada no es un fenómeno reciente y su devenir histórico se puede asemejar de forma clara a las corrientes e influencias de los actores armados que han dominado el panorama sociopolítico nacional a lo largo de los últimos cincuenta años. Como afirman Gil y Alonso (2009), es posible identificar relaciones de colaboración y antagonismo entre los diferentes actores armados, tanto legales como ilegales, de izquierda y derecha, con estructuras vinculadas al crimen organizado, en especial al narcotráfico. Por ello, en Medellín se ha observado por décadas una relación casi indisoluble entre crimen, microtráfico de drogas y otras economías ilegales, y un legado de guerra heredado de las milicias urbanas que ha sido apropiado por bandas y combos delincuenciales.

No obstante, esta confluencia entre actores armados de múltiples orígenes no lleva a desconocer que en Medellín, a diferencia de gran parte de los fenómenos de violencia armada urbana presentes en las ciudades latinoamericanas, se dio un proceso de urbanización del conflicto armado. Este proceso permitió, en un periodo importante de la ciudad, dar una respuesta humanitaria a las consecuencias derivadas del accionar de los múltiples actores presentes en el territorio; es un privilegio con el que no cuentan las ciudades que solo han vivido escenarios de paz.

Los orígenes de la urbanización del conflicto armado en Colombia se pueden hallar en la década del setenta, cuando el Ejército de Liberación Nacional (ELN) insertó estructuras armadas en la ciudad bajo la figura de milicias urbanas. Durante la 
década de los ochenta, se observó la presencia del Movimiento 19 de abril (M-19), quienes no solo identificaron los centros urbanos como zonas de abastecimiento, sino como espacios privilegiados para su labor proselitista ante otros movimientos sociales. Como afirma Medina (2001), la inserción de estos movimientos armados en las actividades urbanas tenía dos pretensiones: incidir en las organizaciones gremiales y realizar labores de reclutamiento al interior de los movimientos sociales y sindicales. Sin embargo, esta labor proselitista en los centros urbanos se complementó con labores de administración de justicia y oferta de seguridad en los barrios, funciones que le permitieron a los miembros de los movimientos subversivos ganar legitimidad y consolidar una estrategia de control territorial y social.

A la par de la incursión urbana de la guerrilla en la década del ochenta, estructuras paramilitares empiezan a ver en la ciudad un atractivo como espacio de operaciones militares, en especial, por la fuerza tomada por el contexto urbano para el accionar de organizaciones criminales ligadas al narcotráfico. "En el caso de Medellín, en la década de los años ochenta, tiene lugar una combinación de formas de violencia organizada: el accionar simultáneo de agentes del narcotráfico, milicias y organizaciones de delincuencia común —bandas—". (Defensoría del Pueblo, 2004. p. 18) Como afirman Deas y Gaitán (1995), en el análisis de los actores que impulsaron la dinámica de confrontación armada en la ciudad no se puede desconocer el papel jugado por el narcotráfico y su violencia explosiva. En este sentido afirman: "El narcotráfico no inventó la violencia, fue posible porque ella existía y persistía desde 1946 como producto de la quiebra del aparato preventivo y represivo del Estado [...] El narcotráfico logró que una violencia muy alta se convirtiera en desbordada" (p. 217).

Bedoya (2010) identifica en la ciudad de Medellín la existencia de dos periodos en materia de protección armada violenta. El primero corresponde a la confrontación Estado-Cartel de Medellín (1989-1993), donde los ataques fueron dirigidos contra policías y la élite. El segundo (1999-2003) se da a partir de la lucha guerrillas-paramilitares, cuando el objeto de ataque fueron facciones armadas contrincantes, como es el caso de las milicias urbanas de la guerrilla o la población civil ubicada en los territorios en disputa. En el primer ciclo, entre 1985 y 1993, se puede afirmar que existió el dominio absoluto de la ciudad por parte del Cartel de Medellín. En este ciclo tuvo relevancia organizaciones sicariales como La Terraza que, entre 1984 y 1998, monopolizó la actividad armada en la ciudad. La transición al segundo ciclo se produce entre 1990 y 1994 debido a la fuerte persecución internacional al Cartel de Medellín, la cual permite un auge de las milicias urbanas asociadas con las FARC, el ELN y la llegada de grupos paramilitares pertenecientes a las Autodefensas Unidas de Colombia, AUC. Desde finales de los noventa hasta mediados de la primera década del 2000 (fecha de la desmovilización), las estructuras paramilitares tomaron el control, inicialmente con el Bloque Metro de las Autodefensas Unidas de Colombia, luego a través del Bloque Cacique Nutibara y, por último, con el Bloque Héroes de Granada. Es así como, 
luego de las operaciones militares que sacudieron la Comuna 13 en el año 2000, "en Medellín, aparentemente pacificada (...) aparecen nuevas manifestaciones de colaboración entre agentes del Estado central y bandas criminales. Su objetivo aparente sería 'civilizar' la actividad criminal o el 'cero tolerancia' a la violencia desembocada" (Palacio y Serrano, 2010, p. 123).

Al fortalecimiento del accionar de estas estructuras paramilitares en la década del noventa e inicios del 2000, contribuyeron indirectamente los grupos de narcotraficantes que, aunque diezmados, nunca perdieron su control en la ciudad. Asimismo, los grupos de seguridad privada se sumaron inicialmente en 1994 con la creación de la Cooperativa de Vigilancia y Servicios Comunitarios (Coosercom) y las Cooperativas de Seguridad Convivir entre 1995 y 1997 como política de gobierno para controlar la criminalidad en el departamento (Defensoría del Pueblo, 2004, p. 38)

Aunque en años posteriores estas cooperativas desaparecieron, sus integrantes entrenados en el uso de armadas, en la mayor parte de los casos, entraron a fortalecer grupos armados ilegales.

Medellín se convirtió, por tanto, en la década de los 90 e inicios del 2000, en el caldo de cultivo propicio para la confluencia de múltiples actores armados, reflejo de la conflictividad violenta que vivía el país, y los cuales fomentaron un crecimiento inusitado de la oferta de seguridad privada violenta, que luego de la desmovilización paramilitar fue el germen del incremento de la violencia en la ciudad por la lucha por el control territorial y de las rentas ilegales. (Valencia, 2018, pp. 72-73)

Cada actor, con sus diferentes estrategias bélicas determinó las consecuencias humanitarias que generaron en la ciudad las guerrillas con reclutamientos, extorsiones, secuestros, entre otros, y los paramilitares con desplazamientos y desapariciones.

Es así como la conflictividad armada en la ciudad se ha caracterizado de forma constante por la disputa por el territorio. Esta disputa puede agruparse en dos ciclos de acuerdo con Bedoya (2010) e interpretados por Valencia (2018) de la siguiente manera:

un ciclo determinado por la disputa del control territorial donde se presenta un repunte de los homicidios selectivos, individuales y colectivos (masacres) como mecanismo tanto de control social como de medio de solución de enfrentamientos entre actores armados, y otro ciclo de implante donde se gana posicionamiento y legitimidad, lo que hace que mecanismos como el cobro de micro extorsiones y las amenazas cobren fuerza. (p. 87)

No obstante, a partir de la segunda mitad de la década del 2000, tras la desmovilización de las estructuras paramilitares, la situación de conflicto armado interno en la ciudad cesó por lo menos desde la perspectiva política, y en los últimos tiempos imperan manifestaciones de violencia armada.

A pesar de esto, algunas consecuencias humanitarias, contrario a lo que podría esperarse, escalaron en los siete años posteriores de la retirada paramilitar. El 
desplazamiento forzado intraurbano creció exponencialmente, pasando de 860 personas desplazadas en 2008 a 9.941 en 2012. Igualmente hubo un repunte de las amenazas: 2.427 en el año 2012. Además, las problemáticas como el reclutamiento forzado y la violencia basada en género se convirtieron en armas de guerra (Personería de Medellín, 2013).

Sin embargo, la categorización de un escenario de este tipo como una situación de violencia urbana y no como conflicto armado no internacional, implica una serie de limitantes para los mandatos de las organizaciones humanitarias. Los operadores humanitarios que enmarcan su accionar desde la perspectiva del humanitarismo clásico (minimalistas) encuentran limitaciones en sus objetivos institucionales para actuar en situaciones que escapan a la concepción clásica de conflicto armado no internacional, y solo persisten en la ciudad actuaciones humanitarias desde la perspectiva maximalista, lideradas por operadores humanitarios con mayor margen de maniobra como las ONGI. Esto deriva en una inadecuada respuesta a las situaciones humanitarias persistentes.

Muestra de ello es que, en el mes de diciembre de 2014, OCHA Naciones Unidas tomó la decisión de cerrar su oficina en Medellín y limitar su foco de interés en los municipios del Norte y Bajo Cauca del departamento antioqueño. Desapareció, entonces, el único espacio de coordinación humanitaria internacional existente. Esto sucedió así a pesar de que, en septiembre de 2014, el Equipo Humanitario Antioquia (EHL) realizó una misión MIRA (Multi-Cluster Initial Rapid Assessment) con la participación de Acnur, Corporación Paz y Democracia, Defensoría del Pueblo, FAO, Handicap International, OCHA, Uariv, Umariv, UNDSS y Usaid, en la que se evidenció una preocupación creciente por las consecuencias humanitarias generadas por la situación de violencia que vivía la ciudad en tres áreas básicas: protección, educación y recuperación temprana (tabla 3).

Tabla 3. Necesidades humanitarias identificadas por el Equipo Humanitario Antioquia (EHL)

Protección

Adolescentes y jóvenes en alto riesgo de ser víctima de reclutamiento forzado, explotación y violencia sexual, homicidio y desaparición forzada, afectados por fronteras invisibles que impiden la libre movilidad.
Educación

Incremento de deserción escolar. Más del $30 \%$ de la población en edad escolar no está recibiendo educación. Algunas escuelas y colegios ya no son considerados sitios de protección. Los alrededores de las escuelas no son seguros o los estudiantes deben cambiar sus rutas de acceso ante las limitaciones de movilidad.
Recuperación temprana - medios de vida

La extorsión a pequeños negocios y actividades económicas afecta significativamente los medios de vida de muchas familias. La estigmatización de los habitantes limita su acceso a trabajos formales.

Fuente: Valencia (2016). 
La protección y atención a la población civil se encuentra entonces restringida a la capacidad de acción de los entes gubernamentales, quienes por su escasa gobernabilidad cuentan con territorios vedados. En este escenario es donde el espacio humanitario cobraría de nuevo importancia.

\section{DEL NEO HUMANITARISMO AL HUMANITARISMO MAXIMALISTA: TRANSFORMACIONES QUE ABREN LA PUERTA AL EJERCICIO DE LA ACCIÓN HUMANITARIA EN CONTEXTO COMPLEJOS}

La acción humanitaria, gracias a su origen común con el Derecho Internacional Humanitario, comparte su espíritu y genera constantes vasos comunicantes. Pero encuentra delimitado su accionar por la concepción clásica del conflicto armado que reduce el mandato de los operadores humanitarios, y en algunos contextos hace de su accionar una respuesta anacrónica — e inadecuada - a las características y necesidades de las manifestaciones actuales de las confrontaciones violentas.

No obstante, los cambios suscitados por el fin de la Guerra Fría en el ámbito de la cooperación internacional (surgimiento en la década de los noventa de una nueva tipología de los conflictos armados y la expansión de la agenda de paz liberal), obligaron a un cuestionamiento de la naturaleza, métodos y objetivos de la acción humanitaria a partir del cual surgió el llamado "nuevo humanitarismo" (Pérez y Zirión, 2010) que hoy se puede caracterizar como un humanitarismo maximalista.

De acuerdo con Barnett (2005), existen múltiples causas para la transformación del humanitarismo, unas globales y otras que corresponden a la esfera interna de las organizaciones. Entre los factores globales se destaca el incremento de los fondos aportados por los estados, como parte de su política exterior, para la respuesta humanitaria y el incremento de las emergencias humanitarias originadas por conflictos intraestatales, además de la reducción de las barreras para la intervención por la flexibilización en las posiciones de los estados en relación con su soberanía (Barnett, 2005). Por otra parte, entre los factores externos es de destacar la cada vez más apremiante necesidad de generar una respuesta humanitaria a las consecuencias de las guerras civiles y las emergencias políticas complejas, así como el aumento de las posiciones críticas con respecto a la ayuda humanitaria (Pérez y Zirión, 2010).

Ahora bien, las transformaciones motivadas por el neo humanitarismo, que hoy hacen de este un enfoque maximalista, no operaron de manera uniforme en todas las organizaciones humanitarias. Como afirma Barnett (2005), dependieron de (1) la identidad de la organización y su comprensión inicial de la relación entre el ser humanitario y la política y de (2) su dependencia de los demás por los recursos materiales y simbólicos. Esto se debe a que la transformación de las estrategias y métodos conllevaba un cambio de fondo en el paradigma de actuación de las agencias humanitarias que les permitió a las más osadas empezar a "aceptar la idea de que podrían tratar de eliminar las causas fundamentales de los conflictos que colocan a los individuos en 
situación de riesgo" (Barnett, 2005, p. 723). Por ende, se empieza a compartir agendas con los Estados, lo que va en total contravía con su carácter apolítico que es el cimiento fundamental de su autodefinición.

De otro lado, se produce un cuestionamiento directo a la indisoluble vinculación entre humanitarismo y DIH. Como afirman Pérez y Zirión (2010) "los marcos teóricos preexistentes, centrados en las guerras interestatales, resultan ahora inadecuados" (p. 12). Por esta razón, una acción humanitaria minimalista delimitada por los contornos del DIH y los principios humanitarios basados en las guerras convencionales del siglo XIX resultan hoy limitados y en algunos casos inoperantes frente a las causas de las nuevas crisis humanitarias en el mundo.

A esto se suma el surgimiento, en la década de los noventa, de la noción de emergencia política compleja, la cual permite reforzar la importancia de la relación entre política y acción humanitaria. Barnett (2005) la define como una

catástrofe humanitaria relacionada con el conflicto que implica un alto grado de descomposición y la dislocación social [caracterizada] por una mezcla combustible de fracaso del Estado, la huida de refugiados, milicias, guerreros refugiados y las poblaciones en situación de riesgo de la violencia, las enfermedades y el hambre. Estas situaciones crean una demanda de nuevos tipos de intervenciones y herramientas de gestión de conflictos. (p. 726)

Emergencias políticas complejas, nuevas crisis humanitarias derivadas de confrontaciones que escapan a la órbita del DIH y un interés creciente por una acción humanitaria que contribuya, desde sus limitaciones, a subsanar las causas que ocasionan los conflictos, son la mejor descripción del panorama que caracteriza las múltiples violencias presentes en Colombia. Particularmente los contextos urbanos representan un caldo de cultivo propicio para la respuesta humanitaria maximalista, ya que la transformación iniciada en los noventa ha continuado ofreciendo alternativas de protección a la población civil afectada por las persistentes consecuencias humanitarias de la violencia armada urbana.

\section{EXPERIENCIAS DE ACCIÓN HUMANITARIA MAXIMALISTA EN CONTEXTOS DE VIOLENCIA ARMADA URBANA: EL CASO DE MEDELLÍN}

De manera excepcional, en contextos donde confluyen situaciones de conflicto armado no internacional y fenómenos de violencia armada urbana, como es el caso colombiano y particularmente de Medellín, las organizaciones humanitarias han implementado acciones que podrían ser entendidas como maximalistas por su orientación a la expansión del ejercicio humanitario. Estas intervenciones se encuentran orientadas, además de salvar vidas y aliviar el sufrimiento, a (1) impulsar labores de advocacy4, (2) promover los derechos humanos y (3) favorecer la construcción de la paz.

La cual consiste en actividades de abogacía e incidencia. 
Esto se podría leer como un primer paso con miras a lograr que la acción humanitaria juegue un papel fundamental en la respuesta a las consecuencias humanitarias generadas por la violencia armada. A pesar de que estas no sean cubiertas por la órbita del DIH, desde la perspectiva de las víctimas las violencias difieren muy poco de las derivadas de una concepción clásica del conflicto armado. En el escenario de confrontación armada actual es cada vez más evidente la necesidad de la apertura de espacios humanitarios ante las limitaciones en materia de control territorial y gobernabilidad por parte de las autoridades locales urbanas.

Por desgracia, como afirma Lucchi (2010):

la ayuda humanitaria en contextos urbanos violentos todavía no se ha convertido en una prioridad (...) Con la excepción de los desastres naturales, los gobiernos donantes siguen generalmente proporcionando poco apoyo financiero a los esfuerzos humanitarios que tienen como objetivo aliviar el sufrimiento inmediato de las personas afectadas por las crisis en los países que no están oficialmente en guerra (p. 985)

Uno de los ejes principales de esta priorización es el modelo de financiación. Los "[m]ecanismos de financiación actuales distinguen entre ayuda al desarrollo, humanitarios y post-conflicto. Los contextos en cuestión se examinan y se clasifican en una de esas categorías, y el dinero de los gobiernos donantes se distribuye en consecuencia" (Lucchi, 2010, p. 986). En esta clasificación, las situaciones de violencia derivadas de problemáticas estructurales por lo general son encasilladas en la órbita de financiación del desarrollo.

Asimismo, determinar el rol que pueden cumplir los operadores humanitarios en contextos de violencia aún es un asunto por explorar. Los operadores humanitarios se sienten intimidados al intentar desarrollar acciones en estos contextos, pero su bagaje en situaciones de conflicto armado constituye una importante experiencia para capitalizar (Lucchi, 2010).

Existen diferentes mecanismos que permiten, de forma más espontánea que intencionada, dar continuidad a la respuesta humanitaria a pesar de la transformación de una situación de conflicto armado en una situación de violencia armada. Se podría afirmar que todas estas acciones que persisten en los escenarios de violencia, como es el caso de la ciudad de Medellín, estarían ubicadas en una perspectiva maximalista, a partir de la cual se introducen nuevos escenarios, objetivos y acciones que escaparían a la lógica del humanitarismo clásico. A continuación, se presenta un caso a partir de la intervención en desastres naturales, el cual permite ilustrar la pervivencia de la intervención humanitaria en contextos de violencia armada. 


\section{INTERVENCIONES DESDE LA ÓRBITA DE LA GESTIÓN DEL RIESGO}

Pese a que de forma arbitraria, en el ámbito humanitario constantemente se trata de hacer la distinción entre las intervenciones enfocadas a las consecuencias humanitarias de los conflictos armados y las derivadas de los desastres naturales, de manera continua la población más vulnerable sufre múltiples afectaciones derivadas de ambas afectaciones, pues sus condiciones socioeconómicas las exponen a riesgos originados en situaciones de violencia y amenazas de origen natural. En este sentido, afirma Smoljan (2003): "Al igual que con la pobreza y la violencia, los desastres naturales y la violencia a menudo se entremezclan" (p. 243). Y lo reafirma Vaux (2006), cuando dice: "En muchos países pobres, el conflicto es una amenaza regular, junto con la falta de lluvias y las inundaciones" (p. 250).

Por ello, existe constante coincidencia entre las áreas de estudios dedicadas a los desastres y los análisis enfocadas en los conflictos armados, y ambas situaciones hacen parte de forma macro de los focos de interés del humanitarismo. Smoljan (2003) afirma: "Dentro de la literatura de desarrollo estándar, el cuerpo de investigación que se ajusta más a las sociedades devastadas por la guerra es el trabajo dedicado a las formas en que las sociedades se recuperan de desastres naturales" (p. 243).

Sin embargo, es importante destacar que, a pesar de la confluencia de múltiples afectaciones en cabeza de una misma persona, es necesario tener presente las diferencias entre las consecuencias humanitarias derivadas de uno u otro escenario humanitario:

En los desastres naturales, hay comunidades identificables para reconstruir, reconocidas autoridades políticas en las áreas que reciben. (...) Los conflictos civiles, por el contrario, pueden durar más de una década y después de los conflictos, la transición es probable que sea muy inestable. (Smoljan, 2003, p. 244)

En los conflictos armados, a diferencia de las situaciones de desastres que buscan reconstruir infraestructuras físicas en la construcción de Estado, la apuesta consiste en recuperar las confianza en las instituciones públicas y fortalecerla.

Desde esta perspectiva, la ONG Internacional Visión Mundial, desde su línea de Acción Humanitaria viene implementando en Colombia desde 2001 un plan de formación para empleados y líderes comunitarios en temas de prevención y manejo de los desastres:

En el 2002-2003 un grupo de representantes comunitarios de los programas de patrocinio en 10 ciudades del país, junto con un grupo de empleados de la ONG establecieron que el modelo de trabajo debía llamarse Ecopad - Equipos Comunitarios para la Prevención y Atención de Desastres. Estos grupos son formados por niños, adolescentes, jóvenes y adultos, y a través de ellos se busca la organización y participación de la comunidad en procesos de prevención, reducción y respuesta oportuna a situaciones de calamidad. (Visión Mundial, 2012, p. 1) 
Los adultos que se vinculan a esta iniciativa son personas que ejercen un rol de liderazgo en sus comunidades. Los niños, niñas, adolescentes y jóvenes también hacen parte de programas de Visión Mundial, como es el caso del Movimiento Nacional Gestores de Paz, el cual da cuenta de la confluencia entre lógicas de acción humanitaria, desarrollo y construcción de paz, totalmente imbricadas en un contexto como el de Medellín. Así como es difícil distinguir los actores armados, los liderazgos también se confunden y refuerzan en una clara preocupación por los riesgos y las amenazas de la ciudad, comprendidos en toda su complejidad.

La relación casi que indisoluble entre las afectaciones generadas por los desastres naturales y el conflicto armado (o en este caso la violencia armada urbana) es también claramente apreciable en las áreas de formación y respuesta seleccionadas por Visión Mundial en su programa. Además de temáticas típicas de respuesta a desastres como brigadistas, cuidado ambiental, diseño e implementación de proyectos para reducir vulnerabilidad y aumentar sus capacidades frente a los desastres y emergencias, el reconocimiento y divulgación de los estándares humanitarios internacionales, se abordan temas como la promoción y defensa de los derechos humanos, la promoción y defensa del Derecho Internacional Humanitario "cuando las personas y comunidades viven situaciones relacionadas con el conflicto armado y la guerra" (Visión Mundial, 2012, p. 3).

En este sentido, los condicionantes del contexto son determinantes para la definición de las temáticas de formación y respuesta. Visión Mundial (2012) afirma en este contexto que "es importante que el Ecopad defina su enfoque de acción de acuerdo a las condiciones propias del contexto, a sus habilidades y competencias" (p. 3).

Esta adecuación al contexto permite que en ciudades como Medellín — según los análisis realizados a partir de la aplicación de los instrumentos planteados en el aparte metodológico-, las habilidades creadas en los jóvenes en materia humanitaria se conviertan en herramientas suficientes para la anticipación de consecuencias, selección y planeación de alternativas de solución de acuerdo con la propuesta de habilitadas cognitivas para la resolución de conflictos (Monjas y González, 2000). En este sentido, el proyecto aporta en estas necesidades específicas, a pesar de que - como los mismos ejecutores del proyecto Ecopad reconocen - no cuenta con un trabajo directo en materia de prevención de la violencia y mucho menos en materia de resolución de conflictos.

Sin embargo, es destacable el hecho de comprender los mecanismos para la "disminución del riesgo, la preparación ante emergencias y la respuesta humanitaria en situaciones de desastre y emergencias, de manera organizada y participativa". (R. Parra, comunicación personal, 28 de octubre de 2015). Es un ejercicio que permite comprender los conceptos formales en materia de resolución de conflictos: causas y tipos de problemas, sentimientos que estos generan, tipos de soluciones posibles, 
consecuencias, alternativas de solución, criterios de evaluación y mecanismos de planificación. Acercar a los niños y niñas a procedimientos básicos de identificación y análisis de consecuencias, generación y búsqueda de alternativas de solución, toma de decisiones, análisis de dificultades, planificación de respuesta y evaluación de resultados, permite la gestión del riesgo. Pero lo más importante es que este método también abre caminos para la solución de problemas interpersonales e n el ámbito cotidiano.

Finalmente, los procesos de organización y participación comunitaria — conformación de equipos comunitarios, prevención y preparación frente a los desastres y emergencias - generan en los jóvenes un cambio de actitud en el que desarrollan un estilo asertivo en la resolución de problemas. En este contexto, se permita tener en cuenta los sentimientos y valorar la importancia que tiene ponerse en el lugar de la otra persona. En esta práctica se dan cuenta que tener autonomía y una actitud abierta a las distintas alternativas de solución son la clave para fortalecer las capacidades de interlocución y liderazgo en momentos de emergencia.

Los Ecopad hoy, más de 10 años después del inicio de la experiencia, son grupos de voluntarios de comunidades en condiciones de vulnerabilidad que se preocupan por reducir el riesgo y se preparan para enfrentar situaciones de emergencia y apoyar la respuesta humanitaria en sus comunidades. Como su misma política institucional afirma: "Son un modelo de organización y participación para la acción humanitaria, viable, duplicable y sostenible, en el territorio nacional. Son en muchos aspectos un actor más en el escenario humanitario" (Visión Mundial, 2012, p. 2).

\section{CONCLUSIONES}

A pesar de que los contextos de violencia armada urbana no han sido comprendidos desde la definición clásica de la acción humanitaria, las consecuencias humanitarias que de ellos se derivan exigen, cada vez de forma más apremiante, una respuesta a las necesidades de la población víctima de fenómenos como el reclutamiento forzado, el desplazamiento, los homicidios selectivos, entre otros.

Los contornos del humanitarismo en las últimas décadas han cambiado junto con las transformaciones producidas post Guerra Fría en las manifestaciones y los orígenes de las confrontaciones armadas, lo cual ha permitido ampliar su órbita, tanto en sus escenarios de intervención como en sus líneas de acción. No obstante, la repuesta en contextos de violencia armada urbana aún es limitada.

Las pocas intervenciones humanitarias que es posible detectar en estos contextos responden básicamente a una lógica de humanitarismo expandido o neo humanitarismo, donde el ejercicio de salvar vidas se persigue por medio de estrategias como la protección de los derechos humanos, la construcción de paz o la prevención de desastres. 
En el caso colombiano, la confluencia de dinámicas de conflicto armado interno con fenómenos de violencia armada urbana, propician un escenario ideal para analizar el impacto de la acción humanitaria en contextos que escapan a su accionar tradicional. Las transiciones en los diferentes tipos de confrontación en Medellín, por ejemplo, han sido tan paulatinas que han permitido la continuidad de acciones humanitarias que solo podrían ser pensadas en escenarios de guerra convencional.

Solo bastaría capitalizar los aprendizajes de estas experiencias para valorar el impacto que la acción humanitaria puede tener en estos contextos y repotenciar la importancia de ampliar su espacio de acción ante los desafíos que se imponen para el contexto latinoamericano a partir las dinámicas de violencia armada urbana.

\section{REFERENCIAS}

Barnett. M. (2005). Humanitarianism Transformed. Perspectives on Politics, 3(4), 723-740. http://academic. udayton.edu/richardghere/NGO\%20Man/Barnett.pdf

Centro Nacional de Memoria Histórica, CNMH. (2013). iBasta ya! Colombia: memorias de guerra y dignidad. Informe general Grupo de Memoria Histórica. http://www.centrodememoriahistorica.gov.co/micrositios/ informeGeneral/

Collier, P. y Hoefflerd, A. (2000), Greed and Grievance in Civil War, World Bank, Policy Research. Working Paper 2355. http://documents.worldbank.org/curated/en/359271468739530199/pdf/multi-page.pdf

Collier, P. (2010). El Club de la Miseria. Radom House Mondadori.

Defensoría del Pueblo. (2004). Desplazamiento intraurbano como consecuencia del conflicto armado en las ciudades.

Deas, M. y Gaitán D. F. (1995) Dos ensayos especulativos sobre la violencia en Colombia. Fonade, Departamento Nacional de Planeación and Tercer Mundo Editores.

Deas, M. (2015). Intercambios violentos. Taurus.

Duncan, G. (2014). Más que plata o plomo. El poder político del narcotráfico en Colombia y México. Debate.

Gaitán, F. (2001). Multicausalidad, impunidad y violencia: una visión alternativa. Revista de Economía Institucional Universidad Externado de Colombia, 5, 78-105.

Gil, M y Alonso, M. (2009). Paramilitarismo y conflicto urbano: relaciones entre el conflicto político armado nacional y las violencias preexistentes en la ciudad de Medellín: 1997-2005 [tesis de maestría, Universidad de Antioquia]. Repositorio Universidad de Antioquia. http://tesis.udea.edu.co/dspace/ bitstream/10495/8587/1/GilMaxY_2010_ParamilitarismoConflictoMedellin.pdf

Galtung, J. (2003): Paz por medios pacíficos. Paz y conflicto, desarrollo y civilización. Bakeaz.

Guzmán Campos, G., Fals Borda, O. y Umaña Luna, E. (2005). La Violencia en Colombia (tomos I y II). Taurus.

Interagency Standing Commitee. (2007). Guía IASC sobre salud mental y apoyo psicosocial en emergencias humanitarias y catástrofes. https://www.acnur.org/5b50c7b82cd.pdf

In Sight Crime. (S. f.). Élites y crimen organizado en Colombia. Consultado el 25 de febrero de 2017. http:// es.insightcrime.org/investigaciones/elites-y-crimen-organizado-en-colombia 
Harroff-Tavel, M. (2010) Violence and humanitarian action in urban areas: new challenges, new approaches. International review of the red cross, 878(92), 329-350. http://www.journals.cambridge. org/abstract_S1816383110000421

Kaldor, M. (2001). Las nuevas guerras. Violencia organizada en la era global. Tusquets Editores.

Kalyvas, S. (2001). La violencia en medio de la Guerra Civil. Esbozo de una teoría. Análisis Político, 42, 3-25. https://revistas.unal.edu.co/index.php/anpol/article/view/75294

Lucchi, E. (2010). Between war and peace: humanitarian assistance in violent urban settings. Disasters, 34(4), 973-995. https://onlinelibrary.wiley.com/doi/abs/10.1111/j.1467-7717.2010.01178.x

Medina, L. (2008). A critique of "resource-based" theories of colombia's civil war. Análisis político, 61, 44-57. http://www.scielo.org.co/pdf/anpol/v21n62/v2ln62a03.pdf

Medina Gallego, C. (2001). ELN: Una historia de los orígenes. Rodríguez Quito Editores.

Monjas, M. I. (1994). Evaluación de la competencia y las habilidades sociales en la edad escolar. En M. A. Verdugo (ed.), Evaluación curricular. Una guía para la intervención psicopedagógica (pp. 423 - 497). Siglo Veintiuno.

Monjas, M. y González, P. (2000). Las Habilidades Sociales en el Currículo. Ministerio de Educación, Cultura y Deporte. http://redined.mecd.gob.es/xmlui/bitstream/handle/11162/58639/008200120100. pdf?sequence $=1$

Neiman, G. y Quaranta, G. (2006). Los estudios de caso en la investigación sociológica. En I. Valsilachis (ed.), Estrategias de Investigación Cualitativa (pp. 213-237). Gedisa Editorial.

Oficina del Alto Comisionado de las Naciones Unidas, Acnudh. (2018). Informe anual del Alto Comisionado de las Naciones Unidas para los Derechos Humanos. https://www.hchr.org.co/documentoseinformes/ informes/altocomisionado/informe2012.pdf

Oficina para la Coordinación de Asuntos Humanitarios Naciones Unidas. (2015). Infograma Situación Humanitaria en Colombia Primer Semestre 2015. http://www.hchr.org.co/index.php/informes-ydocumentos/informes-anuales/8887-informe-del-alto-comisionado-de-las-naciones-unidaspara-los-derechos-humanos-sobre-la-situacion-de-derechos-humanos-en-colombia-duranteel-ano-2017

Oficina para la Coordinación de Asuntos Humanitarios Naciones Unidas, OCHA-Umaic. (2018). Tendencias Humanitarias Colombia (enero 2015-diciembre 2017). https://www.humanitarianresponse.info/ sites/www.humanitarianresponse.info/files/documents/files/180621_tendencias_humanitarias_ periodo_2015_a_2017_vf_.pdf

Oficina para la Coordinación de Asuntos Humanitarios Naciones Unidas, OCHA-Umaic. (2019). Boletín Humanitario Colombia (diciembre 2018). https://www.humanitarianresponse.info/sites/www. humanitarianresponse.info/files/documents/files/boletin_humanitario_nuevoformato_vf.pdf

Palacios, M. y Serrano, M. (2010). Colombia y México: las violencias del narcotráfico, en Seguridad nacional y seguridad interior. En A. Alvarado, y M. Serrano (eds.). Los grandes problemas de México. Tomo XV (pp. 105-154). El Colegio de México.

Pérez, K. y Zirión, I. (2010). La acción humanitaria como instrumento para la construcción de la paz. Herramientas, potencialidades y críticas. Cuadernos de Trabajo de Hegoa, 51. http://publicaciones.hegoa.ehu.es/ es/publications/209 
Personería de Medellín. (2013). Informe sobre la situación de los derechos humanos en la ciudad de Medellín 2012. http://www.personeriamedellin.gov.co/index.php/informacion-al-ciudadano/documentos/ informes-derechos-humanos-ddhh/category/38-informes-ddhh-2015\#

Sánchez, G. y Meertens, D. (1983). Bandoleros, gamonales y campesinos. El caso de la Violencia en Colombia. El Ancora Editores.

Sen, A. (1996) Capacidad y Bienestar. En M. Nussbaum y A. Sen (eds.), La Calidad de Vida. Fondo de Cultura Económica

Sen, A. (1998). Capital Humano y capacidad humana. Cuadernos de economía, 29, 69-72.

Smoljan, J. (2003). The Relationship Between Peace Building and Development. Conflict, Security and Development, 3(2), 233-255.

Uribe, M. (2011) Lo político en La guerra civil colombiana. Análisis político, 72, 23-42.

Valencia, P. (2016). La respuesta humanitaria entre los debates teóricos y la crisis de la gobernabilidad en los contextos urbanos latinoamericanos: el caso de Medellín. En I. Mosel, C. Bennett y H. Krebs (eds.). Aproximaciones a la historia del humanitarismo en América Latina y el Caribe (pp. 61-72). Overseas Development Institute. https://www.odi.org/publications/10665-aproximaciones-lahistoria-del-humanitarismo-en-am-rica-latina-y-el-caribe

Valencia, P. (2018). Los ciclos de la violencia ligada al narcotráfico en Colombia y México, una expresión de la ruptura de pactos con elites locales y nacionales. En M. Nateras, y P. Valencia (eds.), Políticas de seguridad y entornos violentos en Colombia y México (pp. 55- 98). Sello Editorial Universidad de Medellín.

Vaux, T. (2006) Humanitarian trends and dilemas. Development in Practice, (16), 240-254. https://www. tandfonline.com/doi/full/10.1080/09614520600694653

Visión Mundial. (2012). Modelo de Organización y Participación Comunitaria VMcol- Equipos Comunitarios para la Prevención y Atención de desastres - Ecopad. 